\title{
Personal Birth Order Affects Subjective Well-Being-Empirical Analysis Based on CFPS Data
}

\author{
Qiaofang Shi \\ College of Economics, Jinan University, Guangzhou, China \\ Email: quphen@126.com
}

How to cite this paper: Shi, Q. F. (2020). Personal Birth Order Affects Subjective Well-Being-Empirical Analysis Based on CFPS Data. Open Journal of Social Sciences, $8,377-391$.

https://doi.org/10.4236/jss.2020.85026

Received: April 20, 2020

Accepted: May 26, 2020

Published: May 29, 2020

Copyright $\odot 2020$ by author(s) and Scientific Research Publishing Inc. This work is licensed under the Creative Commons Attribution International License (CC BY 4.0).

http://creativecommons.org/licenses/by/4.0/

\section{(c) (i) Open Access}

\begin{abstract}
Whether the order of personal birth affects subjective well-being is a question to be tested. This paper uses CFPS2010 data to conduct an empirical study on the relationship between personal birth order and subjective well-being. The main findings of this article are as follows: First, the order of birth (the value from small to large means that the child is born from first to last) has a significantly negative impact on happiness. Second, there is a gender difference in the negative impact of birth order on happiness.
\end{abstract}

\section{Keywords}

Absolute Birth Order, Relative Birth Order, Subjective Well-Being

\section{Introduction}

Happiness is usually regarded as the ultimate goal of life, and almost everyone wants to be happy (Frey \& Stutzer, 2002). As China enters the decisive stage of building a moderately prosperous society in all respects, we need to unite all possible people and mobilize all positive factors. Therefore, it is of practical significance to pay attention to people's happiness.

What factors are related to people's happiness? With the development of science and the progress of society, people gradually realize that "birth order" has a profound impact on individual psychological development (Luo \& Li, 2017). People of the same birth order tend to have similar personality characteristics: the words associated with eldest children are usually responsible, organized, independent, conventional, conservative, etc., while the words associated with the youngest children are coddled, creative, and playful (Adler, 1998). So does an individual's birth order affect their happiness? 
According to existing research, a powerful factor that affects individual well-being is the economic factor. At a particular stage in a country, people with higher incomes are, on average, happier; however, raising everyone's income does not increase everyone's well-being (Easterlin, 1995). The higher the relative income, the stronger the subjective well-being, but this effect is different in different income groups (Ferrer-i-Carbonell, 2005). There is a significant positive correlation between absolute income and subjective well-being, but the correlation between subjective well-being and income level is not high, and non-income factors deserve further attention (Luo, 2009). Tian Guoqiang and Yang Liyan (2006) theoretically discuss the relationship between income and happiness. The results show that there is a critical income level which is positively correlated with the immaterial initial endowment. Once this critical income level is reached or exceeded, increasing income actually reduces overall happiness. Research on the effect of income inequality on subjective well-being has not reached a consensus; while on the relationship between inflation and well-being; most economists agree that there is a negative correlation between them (Lu \& Wang, 2010). In terms of unemployment, Van der Meer (2014) explains why unemployment has a serious impact on people's subjective well-being: because unemployment affects both the satisfaction of material life and social identity.

A large part of the literature also explores the influence of social factors on individual well-being. At present, China has entered a stage in which economic growth has gradually weakened the role of improving national happiness. Improving people's livelihood has a greater effect on national well-being; the improvement of public service satisfaction significantly improves the individual's life satisfaction, which has a greater impact on life satisfaction than income (Zhou et al., 2015). Government quality significantly affects residents' well-being, and its promotion effect on residents' well-being is much higher than economic growth (Chen \& Li, 2012). Li Tao et al. (2011) studied the impact of family-owned housing on residents' well-being, and the results showed that there were significant differences in the impact of different types of property-owned housing on residents' well-being. Owning houses with full property rights and having more of them can significantly increase residents' happiness, but the number of houses with limited property rights and the number of them have no significant impact on residents' well-being. Much of the cross-country research literature on happiness economics proves that residents of rich countries are happier than those of poor countries (Lu \& Wang, 2010).

In addition to economic and social factors, it should be noted that personal well-being is closely related to individual characteristics. Li Lei et al. (2017) studied for the first time the differences in gender well-being in China and the causes, and found that women's well-being in China is significantly higher than men's. The higher the education level, the higher the family income and the healthier the person, the higher the happiness (Lu et al., 2017). Jin Jiang and $\mathrm{He}$ Lihua (2012) used the survey data of the subjective well-being of urban residents 
in Wuhan in 2007 to discuss the relationship between education and subjective well-being, and found that whether education is measured by education level or years of education, education has a significant positive impact on subjective well-being. People around the age of 40 have the most stress and the least happiness (Lu et al., 2017); Ohtake (2012) also found that middle-aged unemployed people in Japan around the age of 40 have the lowest happiness. Marriage has a positive effect on happiness (Frijters et al., 2004). Values are also an important factor affecting residents' well-being (Zhang \& Cai, 2011). Furdyna et al. (2008) surveyed 431 working wives in 21 cities in the United States. The results showed that for women with traditional values, the higher their income relative to their husbands, the lower their happiness. Among white women, the higher the family's income relative to the husband's was, the happier they were when the family experienced financial difficulties. Personality characteristics, especially extroversion and neuroticism, are considered to be the main factors affecting subjective well-being; however, the causal connection between personality and subjective well-being has not yet achieved significant research results (Tian, 2004). Temperament type affects personal well-being. Subjects of different temperament types have extremely significant differences in the total score of subjective well-being (Jiang \& Bai, 2009). In addition, for Chinese people, religious belief can alleviate the negative effects of physical health on well-being, and this improvement is particularly obvious for individuals with many physical health problems (Wang et al., 2014).

Individual happiness is influenced by individual characteristics, while birth order has an impact on individual personality and behavioral development (Adler, 1998). Adler, a pioneer in individual psychology, was an early researcher on birth order. Although the birth order is not the only explanatory factor for personality development, it is an important factor. Sulloway, an evolutionary psychologist, agrees that first-born children are usually responsible for the family, with a sense of responsibility and conservative thinking.

Black et al. (2005) found that late-born children performed much worse in school. Weng et al. (2019) used data from the 2013 China Family Income Project Survey (CHIPs) to find that children with a lower birth order have higher education levels, and this effect is more pronounced in families where the first child is a girl and the family has financial difficulties. On the contrary, the confluence model of psychology uses the average age of family members to represent the intellectual environment of the child. Later born children have poor intellectual environment due to the birth of one or more siblings in the family. Therefore, the model predicts that birth order has a negative impact on educational attainment (Becker, 1981; Behrman, 1997). Price (2008) also concluded that there is a negative correlation between birth order and educational attainment. In fact, most studies have shown that a higher birth order hinders cognitive development and lowers educational attainment (De Haan et al., 2014). In terms of birth order and height, Jayachandran and Pande (2017) used data from 168,000 child- 
ren and found that the height of Indian children decreased with increasing birth order. After analysis and testing, the author believes that this is due to the preference for the eldest son, and the factor of birth order alone can explain more than half of the height differences between Indian and African children. De Haan et al. (2014) studied the influence of birth order on human capital in Ecuador and found that there was a positive birth order effect: from early childhood to adolescence, early-born children are lagging behind in the development of human capital.

Individual characteristics affect individual well-being, and individual characteristics are affected by birth order. Therefore, whether the order of personal birth will affect subjective well-being is a question to be tested, and this article investigates this issue. Investigating the influence of birth order on happiness is a supplement to the current research literature on happiness. Easterlin first focused on the relationship between income and happiness, and later studies on happiness focused on the influence of economic and macroeconomic factors, social factors and individual characteristics on happiness. However, no article considered the birth order of individuals. It also complements the current literature on birth order. The influence of birth order on individual characteristics has long been concerned by psychologists, but few economists use economic methods to analyze it. Based on the econometric method, this paper studies the influence of birth order from the perspective of economics, which can undoubtedly provide empirical evidence for the psychological proposition "individual characteristics are influenced by birth order" and enrich its research methods.

The rest of the paper is organized as follows: Section 2 introduces the source of data and basic characteristics of the main variables; Section 3 reports the econometric regression results and analysis; Section 4 summarizes the full text.

\section{Data and Variables}

\subsection{Source of Data}

The data used in this paper is taken from the China Family Panel Studies (CFPS), which was implemented by the China Social Science Investigation Center (ISSS) of Peking University. The survey was pre-investigated in 2008 and 2009 , and a baseline survey was formally conducted in 2010, and a full sample follow-up survey was conducted in 2012, 2014, 2016, and 2018. Among them, only the 2010 survey asked respondents questions about their siblings (such as number, age, gender, etc.), so the key variable "birth order" in this paper can only be provided by the 2010 baseline survey. Therefore, this paper uses the data from the 2010 CFPS survey. The 2010 baseline survey interviewed a total of 14,960 households and 42,590 individuals. The sample covers 25 provinces/cities/autonomous regions and represents $95 \%$ of China's population.

\subsection{Definition of Variables}

The core independent variable in this paper is the birth order, and the common 
one is the absolute birth order, that is, "ranking". However, for different family sizes, Luo Kai and Zhou Li'an (2010) pointed out that the absolute birth order may mix different characteristics, causing estimation bias. The solution to this problem is to construct relative birth order indicators. Referring to Luo Kai and Zhou Li'an (2010), if the number of children in a family is $N$, then the formula for calculating the relative birth order $R_{k}$ of individual $k$ is $R_{k}=\frac{k}{\frac{1}{N} \sum_{m=1}^{N} m}=\frac{k}{\frac{N+1}{2}}$.

The biggest advantage of this indicator is that the relative birth order index of each child in the family is 1 , so it is completely independent of the number of children, which is equivalent to the standardization of the number of children. Absolute birth order is denoted by Arank and relative birth order by Rrank. The dependent variable is the respondent's answer to the question "How happy do you think you are", and the measure is a score from 1 to 5 . The higher the score, the stronger the score of happiness. In the following, happiness is expressed by Happiness.

The research on the influence of birth order on subjective well-being also needs to control for other related variables. According to existing literature, personal subjective happiness may be related to one's age, gender, health status, years of education, marital status, living area and nationality. In addition to this, one's income should be considered as the basic factor affecting happiness. Parental education may also affect an individual's quality of life in childhood and perception of happiness. As a result, this paper considers the following factors: 1) Age, denoted by Age. 2) Gender, denoted by Gender. 1 means one is male, 0 means female. 3) Health, denoted by Health. Evaluation of your physical health is from 1 (healthy) to 5 (very unhealthy). 4) Income, denoted by Income, Personal income. 5) Years of education, denoted by Edu. 6) Marriage status, denoted by Marriage. 1 means one is married, 0 means unmarried, cohabiting, divorced or widowed. 7) Whether to live in the city, use Urban to indicate. 1 represents a person living in the city, 0 represents living in the countryside. 8) Nation, denoted by Nation. 1 means a person is a Han nationality, 0 means another nationality. 9) Father's highest education, denoted by Fedu, from 1 (illiterate/semi-illiterate) to 8 (doctorate). 10) Mother's highest education, denoted by Medu, from 1 (illiterate/semi-illiterate) to 8 (doctorate).

Table 1 shows the corresponding relationship between personal subjective well-being and ranking distribution. The description of each main variable index is shown in Table 2.

\section{Econometric Regression Results}

\subsection{The Preliminary Analysis}

Is happiness related to ranking? To explore the answer to this question primarily, considering that there is no ranking index for only children, we can investigate whether there is a significant difference in the score of happiness between 
the only-child group and the non-only-child group. A total of 31,458 data from 28,597 non-only children and 2861 only children of CFPS2010 adult database were used for exploration. After testing the homogeneity of the variances of the two groups, it is found that the $\mathrm{p}$-value of the two groups with equal variances is 0.0001 , that is, the variances of the two groups are not equal. Therefore, the mean $\mathrm{T}$ test with uneven variances of the two samples is conducted. The null hypothesis is that there is no significant difference in the happiness of the only child and non-only child groups. The results are shown in Table 3. The original hypothesis is accepted has a p-value of 0.001 , which means there is insufficient evidence to prove that the null hypothesis can be accepted, that is, there is a significant difference in the average happiness of the two.

Table 1. Ranking structure of personal subjective well-being.

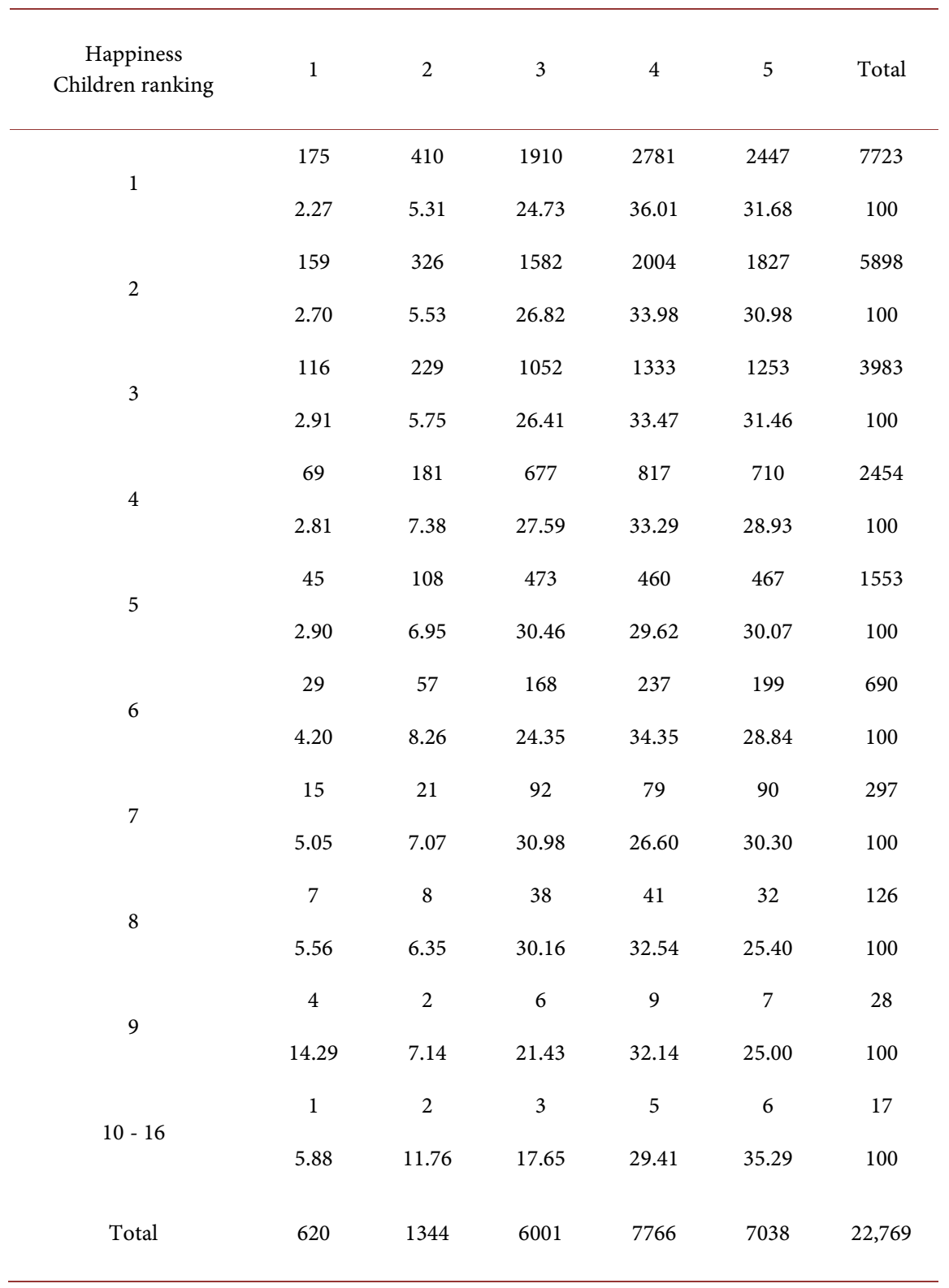


Table 2. Data characteristics of main variables.

\begin{tabular}{cccccc}
\hline Variable & $\mathrm{N}$ & Mean & S.D & Min & Max \\
\hline Happiness & 22,769 & 3.85 & 1.01 & 1 & 5 \\
Arank & 22,769 & 2.49 & 1.57 & 1 & 16 \\
Rrank & 22,769 & 0.95 & 0.43 & 0.15 & 1.88 \\
Age & 22,769 & 45.30 & 14.65 & 16 & 91 \\
Gender & 22,769 & 0.48 & 0.50 & 0 & 1 \\
Health & 22,769 & 1.82 & 1.01 & 1 & 5 \\
Income & 22,769 & 9855.52 & 19,939 & 0 & 800,000 \\
Edu & 22,769 & 6.96 & 4.57 & 0 & 22 \\
Marriage & 22,769 & 0.86 & 0.35 & 0 & 1 \\
Urban & 22,769 & 0.43 & 0.50 & 0 & 1 \\
Nation & 22,769 & 0.92 & 0.28 & 0 & 1 \\
Fedu & 22,769 & 1.82 & 1.05 & 1 & 8 \\
Medu & 22,769 & 1.40 & 0.77 & 1 & 8 \\
\hline
\end{tabular}

Table 3. Two-sample t test with unequal variances.

\begin{tabular}{ccccccccc}
\hline & obs 1 & obs 2 & Mean 1 & Mean 2 & dif & St_Err & t_value & $p_{-}$value \\
\hline $\begin{array}{c}\text { Happiness } \\
\text { by onlyc 1 }\end{array}$ & 28,597 & 2861 & 3.829 & 3.896 & -0.068 & 0.02 & -3.35 & 0.001 \\
\hline
\end{tabular}

If the three levels with lower Happiness values (1,2 and 3) are classified as "unhappiness", the highest two levels (4 and 5) are classified as "happiness", and the variable is named Happy. Here, Happy is a binary variable, which specifies a value of 0 if the answer is "unhappiness" and a value of 1 if the answer is "happiness". Similarly, use the variable Happy to investigate once again whether there is a significant difference in the sense of well-being between the only-child group and the non-only-child group. The results are shown in Table 4. It can also be found that there is a significant difference in the average happiness of the two groups.

\subsection{Basic Regression}

Considering the uniqueness of the one-child ranking problem, the following regression in this paper only builds the following models for the non-only children sample:

$$
\text { Happiness }_{i}=\alpha+\beta \text { Arank }_{i}+\theta X_{i}+\varepsilon_{i}
$$

For the above known reasons, the following model is also constructed for the sample of non-only children:

$$
\text { Happiness }_{i}=\alpha+\beta \operatorname{Rrank}_{i}+\theta X_{i}+\varepsilon_{i}
$$

Among them, Happiness means happiness, Arank means absolute birth order, Rrank means relative birth order, and $X$ means other control variables. First, 
OLS is used for the regression of happiness. Second, for model (1), considering that subjective well-being is a grade variable, the ordered selection model (Ologit) was used to return to verify the robustness of birth order to the relationship of happiness. The regression results are shown in Table 5.

Table 4. Two-sample t test with unequal variances.

\begin{tabular}{ccccccccc}
\hline & obs 1 & obs 2 & Mean 1 & Mean 2 & dif & St_Err & t_value & $p_{-}$value \\
\hline $\begin{array}{c}\text { Happy } \\
\text { by onlychild 1 }\end{array}$ & 28,597 & 2861 & 0.644 & 0.687 & -0.042 & 0.009 & -4.5 & 0 \\
\hline
\end{tabular}

Table 5. Regression results of birth order and happiness.

\begin{tabular}{|c|c|c|c|}
\hline & (1) & (2) & (3) \\
\hline & OLS & OLS & Ologit \\
\hline & Happiness & Happiness & Happiness \\
\hline \multirow[t]{2}{*}{ Arank } & $-0.0275^{* * *}$ & & $-0.0463^{* * *}$ \\
\hline & $(-6.44)$ & & $(-5.78)$ \\
\hline \multirow[t]{2}{*}{ Rrank } & & $-0.0471^{* *}$ & \\
\hline & & $(-3.09)$ & \\
\hline \multirow[t]{2}{*}{ Age } & $0.00511^{* * *}$ & $0.00487^{* * *}$ & $0.00957^{* * *}$ \\
\hline & $(9.73)$ & $(9.25)$ & $(9.81)$ \\
\hline \multirow[t]{2}{*}{ Gender } & $-0.131^{* * *}$ & $-0.130^{* * *}$ & $-0.233^{* * *}$ \\
\hline & $(-9.64)$ & $(-9.57)$ & $(-9.15)$ \\
\hline \multirow[t]{2}{*}{ Health } & $-0.202^{* * *}$ & $-0.203^{* * *}$ & $-0.361^{* * *}$ \\
\hline & $(-29.57)$ & $(-29.66)$ & $(-27.38)$ \\
\hline \multirow[t]{2}{*}{ Income } & $0.00000159^{* * *}$ & $0.00000160^{* * *}$ & $0.00000287^{* * *}$ \\
\hline & $(4.60)$ & $(4.62)$ & $(4.10)$ \\
\hline \multirow[t]{2}{*}{ Edu } & $0.0196^{* * *}$ & $0.0196^{* * *}$ & $0.0343^{* * *}$ \\
\hline & $(11.10)$ & (11.09) & $(10.45)$ \\
\hline \multirow[t]{2}{*}{ Marriage } & $0.208^{* * *}$ & $0.199^{* * *}$ & $0.348^{* * *}$ \\
\hline & $(10.92)$ & $(10.48)$ & $(9.76)$ \\
\hline \multirow[t]{2}{*}{ Urban } & $0.0448^{* *}$ & $0.0446^{* *}$ & $0.0832^{* *}$ \\
\hline & $(3.13)$ & $(3.11)$ & $(3.11)$ \\
\hline \multirow[t]{2}{*}{ Nation } & $0.0647^{* *}$ & $0.0646^{* *}$ & $0.116^{* *}$ \\
\hline & $(2.73)$ & $(2.72)$ & $(2.65)$ \\
\hline \multirow[t]{2}{*}{ Fedu } & 0.00499 & 0.00736 & 0.0121 \\
\hline & $(0.66)$ & $(0.97)$ & $(0.85)$ \\
\hline \multirow[t]{2}{*}{ Medu } & $0.0409^{* * *}$ & $0.0457^{* * *}$ & $0.0689^{* * *}$ \\
\hline & $(3.94)$ & $(4.41)$ & $(3.55)$ \\
\hline \multirow[t]{2}{*}{ _cons } & $3.638^{* * *}$ & $3.622^{* * *}$ & \\
\hline & $(86.20)$ & $(82.63)$ & \\
\hline$N$ & 22,769 & 22,769 & 22,769 \\
\hline
\end{tabular}

$t$ statistics in parentheses. ${ }^{*} p<0.05,{ }^{* *} p<0.01,{ }^{* * *} p<0.001$. 
The OLS regression results show that the coefficient of birth order is negative and statistically significant. The OLS coefficient shows that keeping other variables unchanged, raising the order of birth by an average reduces subjective well-being by $0.028-0.047$ points. From the perspective of control variables, age is a key factor influencing well-being, and the increase of age helps to improve well-being. Compared with men, women have a higher score of happiness, which is consistent with the findings of Li Lei et al. (2017). Health status has a great influence on well-being. The worse the physical condition, the lower the well-being. Personal income and education levels have a significant positive effect on happiness. Marriage has a significant positive effect on happiness, consistent with the findings of Yuan Zheng and Li Ling (2017). People living in cities are happier than those living in rural areas. On average, the happiness of the Han people is a little higher than that of other peoples. Compared with the father's education status, the mother's education status can affect the individual's well-being more, probably because the mother is the child's first teacher, which plays a subtle role in personal education.

Ologit regression results show that the coefficient of birth order is negative and statistically significant. The ologit coefficient indicates that keeping other variables unchanged, the increase in birth order will significantly reduce personal subjective well-being. When an individual's absolute birth order is increased by one level, the likelihood that happiness increases by one level or more will be reduced by 0.045 times. Similar to OLS regression, from the perspective of control variables, age, gender, health status, marital status, whether living in the city, whether it is the Han people, and the education status of the mother can all significantly affect personal happiness. Father's educational status had no significant effect on individual happiness.

If the three levels with lower Happiness values (1, 2 and 3) are classified as "unhappiness", the highest two levels (4 and 5) are classified as "happiness", and the variable is named Happy. Here, Happy is a binary variable, which specifies a value of 0 if the answer is "unhappiness" and a value of 1 if the answer is "happiness". By replacing the dependent variables of models (1) and (2), models (3) and (4) are obtained.

$$
\begin{aligned}
& \text { Happy }_{i}=\alpha+\beta \operatorname{Rrank}_{i}+\theta X_{i}+\varepsilon_{i} \\
& \text { Happy }_{i}=\alpha+\beta \operatorname{Rrank}_{i}+\theta X_{i}+\varepsilon_{i}
\end{aligned}
$$

The probit method was used for the regression of models (3) and (4) to verify the robustness of absolute birth order on the relationship of happiness. The regression results are shown in Table 6.

The regression results also show that the coefficient of birth order is negative and statistically significant. Probit coefficient shows that keeping other variables unchanged, the increase in birth order will significantly reduce personal subjective well-being. Similar to OLS and Ologit regression, from the perspective of control variables, age, gender, health status, marital status, whether they live in 
the city, whether they are Han people, and the mother's education status can significantly affect personal happiness, and fathers' educational status had no significant effect on individual happiness.

Whether OLS or Ologit models were used, whether the independent variable was absolute birth order or relative birth order, and whether the classification of happiness was reclassified, the coefficient of birth order was significantly negative, meaning that people born later had lower happiness.

Table 6. Regression results of birth order and happiness (Probit).

\begin{tabular}{|c|c|c|}
\hline & (1) & (2) \\
\hline & Happy & Happy \\
\hline \multirow[t]{2}{*}{ Arank } & $-0.0372^{* * *}$ & \\
\hline & $(-6.56)$ & \\
\hline \multirow[t]{2}{*}{ Rrank } & & $-0.0728^{* * *}$ \\
\hline & & $(-3.59)$ \\
\hline \multirow[t]{2}{*}{ Age } & $0.00677^{* * *}$ & $0.00643^{* * *}$ \\
\hline & $(9.63)$ & $(9.12)$ \\
\hline \multirow[t]{2}{*}{ Gender } & $-0.154^{* * *}$ & $-0.152^{* * *}$ \\
\hline & $(-8.40)$ & $(-8.33)$ \\
\hline \multirow[t]{2}{*}{ Health } & $-0.217^{* * *}$ & $-0.217^{* * *}$ \\
\hline & $(-24.12)$ & $(-24.22)$ \\
\hline \multirow[t]{2}{*}{ Income } & $0.00000390^{* * *}$ & $0.00000393^{* * *}$ \\
\hline & $(6.04)$ & $(6.09)$ \\
\hline \multirow[t]{2}{*}{ Edu } & $0.0205^{* * *}$ & $0.0205^{* * *}$ \\
\hline & $(8.65)$ & $(8.65)$ \\
\hline \multirow[t]{2}{*}{ Marriage } & $0.187^{* \star *}$ & $0.176^{* * *}$ \\
\hline & $(7.47)$ & $(7.05)$ \\
\hline \multirow[t]{2}{*}{ Urban } & $0.0420^{*}$ & $0.0417^{*}$ \\
\hline & $(2.19)$ & $(2.18)$ \\
\hline \multirow[t]{2}{*}{ Nation } & $0.0773^{*}$ & $0.0775^{*}$ \\
\hline & $(2.48)$ & $(2.49)$ \\
\hline \multirow[t]{2}{*}{ Fedu } & 0.0103 & 0.0132 \\
\hline & $(1.02)$ & $(1.31)$ \\
\hline \multirow[t]{2}{*}{ Medu } & $0.0436^{* *}$ & $0.0497^{* * *}$ \\
\hline & $(3.10)$ & $(3.54)$ \\
\hline \multirow[t]{2}{*}{ _cons } & $0.144^{* *}$ & $0.132^{*}$ \\
\hline & $(2.58)$ & $(2.28)$ \\
\hline$N$ & 22,769 & 22,769 \\
\hline
\end{tabular}

$t$ statistics in parentheses. ${ }^{*} p<0.05,{ }^{* *} p<0.01,{ }^{* * *} p<0.001$. 


\subsection{Further Regression and Analysis}

\subsubsection{The Relationship between Birth Order and Happiness of Individuals of Different Genders: Further Regression}

In the basic regression, whether the birth order is measured in absolute birth order or relative birth order, the birth order effect is significantly negative at least at the $95 \%$ significance level. On the basis of basic regression, Table 7 and Table 8 list the regression results of male and female samples, respectively. It can be seen from Table 7 and Table 8 that the effect of individual absolute birth order on happiness is always significantly negative, which is consistent with the above results.

In Table 7, when relative birth order index is used to measure birth order, the coefficients of columns (4) and (5) are consistent with the previous results, and the birth order effect is negative but not significant. In column (6), the birth order effect is negative and the significance level is $90 \%$, which is lower than the basic regression level. In Table 8 , this effect is still all negative. The significance level is $95 \%$, and the coefficients in columns (4)-(6) are larger than the absolute values of the corresponding male coefficients. This result implies that there are gender-related structural differences in the birth order of individuals. Overall, although children born later were less happy than those born earlier, the later they were born within the family, the greater the negative impact on women's happiness.

Table 7. The influence of personal birth order on male happiness.

\begin{tabular}{ccccccc}
\hline & $(1)$ & $(2)$ & $(3)$ & $(4)$ & $(5)$ & $(6)$ \\
\hline & OLS & Ologit & Probit & OLS & Ologit & Probit \\
\hline \multirow{2}{*}{ Arank } & Happiness & Happiness & Happy & Happiness & Happiness & Happy \\
& $-0.0293^{* * *}$ & $-0.0487^{* *}$ & $-0.0396^{* *}$ & & & \\
\multirow{2}{*}{ Rrank } & $(-4.74)$ & $(-4.24)$ & $(-4.89)$ & & & \\
& & & & -0.0370 & -0.0555 & $-0.0674^{*}$ \\
X & & & & $(-1.67)$ & $(-1.36)$ & $(-2.31)$ \\
$N$ & 10,938 & 10,938 & 10,938 & 10,938 & 10,938 & 10,938 \\
\hline
\end{tabular}

$t$ statistics in parentheses. ${ }^{*} p<0.05,{ }^{* *} p<0.01,{ }^{* * *} p<0.001$.

Table 8. The influence of personal birth order on women's happiness.

\begin{tabular}{|c|c|c|c|c|c|c|}
\hline & (1) & (2) & (3) & (4) & (5) & (6) \\
\hline & OLS & Ologit & Probit & OLS & Ologit & Probit \\
\hline & Happiness & Happiness & Happy & Happiness & Happiness & Happy \\
\hline \multirow[t]{2}{*}{ Arank } & $-0.0259^{\star * *}$ & $-0.0442^{\star * *}$ & $-0.0347^{\star * *}$ & & & \\
\hline & $(-4.38)$ & $(-3.95)$ & $(-4.38)$ & & & \\
\hline \multirow[t]{2}{*}{ Rrank } & & & & $-0.0561^{* *}$ & $-0.102^{\star *}$ & $-0.0770^{\star *}$ \\
\hline & & & & $(-2.67)$ & $(-2.58)$ & $(-2.72)$ \\
\hline $\mathrm{X}$ & $\mathrm{Y}$ & $\mathrm{Y}$ & $\mathrm{Y}$ & $\mathrm{Y}$ & $\mathrm{Y}$ & $\mathrm{Y}$ \\
\hline$N$ & 11,831 & 11,831 & 11,831 & 11,831 & 11,831 & 11,831 \\
\hline
\end{tabular}




\subsubsection{The Difference in Happiness between the First Child and the Second Child in a Two-Child Family: Further Analysis}

To further analyze the gender difference between birth order and happiness, the next step is to investigate whether there is a difference in the happiness of the first child and the second child in two families of different genders. The reason for choosing a family with two children is there are more families with two children, and the gender combination of the two children is less, which is convenient for comparison between different families. The two children are in the same family and the growth environment is basically the same. For the sake of simplicity, we investigated whether there is a difference in the happiness of the two children in the families with two boys and the families with two girls.

The results of the analysis on whether there is a difference in the happiness of children from families with two boys are shown in Table 9. From the table, it can be seen that the p-value of the first and the second child is not different. The p-value is 0.038 , which is less than 0.05 , which means that there is not enough evidence to accept the null hypothesis that there is no difference in the happiness of the first and second children. That is, in families with two boys, there was a significant difference in the happiness of the two children, and their birth order affected their happiness.

The results of the analysis on whether there is a difference in the happiness of children from families with two girls are shown in Table 10. As can be seen from the table, the $\mathrm{p}$ value of no difference in the happiness of the first and second children is 0.424 , which is greater than 0.05 . There is enough evidence to prove that the null hypothesis that there is no difference in the happiness of the first and second children is acceptable. That is, there was no significant difference in the happiness of the first and second children in the families with two girls, and the ranking did not affect happiness.

The above analysis shows that ranking affects well-being and there are also gender differences.

\section{Conclusion}

In this paper, through the analysis of the 2010 adult database data of the Chinese Family Tracking Survey, it is found that the birth order has a significantly negative impact on happiness, and there are gender differences. OLS regression, ordered logit regression and Probit regression all show that the larger the birth order, the lower the individual's subjective well-being. According to the regression results of the gender group, if the gender composition of children was mixed with all families, the birth order had a negative influence on both men and women, but the relative birth order of men and women in family had a more significantly negative influence on women. Further analysis of the family of two children found that if it was a family with two boys, under the same family environment, the happiness of the second child was significantly lower than that of the first; while in the family with two girls, there was no significant difference in the children's happiness. 
Table 9. The mean t-test for differences in the happiness of the first and second children of families with two boys.

\begin{tabular}{ccccccccc}
\hline & obs 1 & obs 2 & Mean 1 & Mean 2 & dif & St_Err & t_value & $p$ _value \\
\hline $\begin{array}{c}\text { Happiness by } \\
\text { Arank 2 }\end{array}$ & 404 & 372 & 4.045 & 3.903 & 0.141 & 0.068 & 2.1 & 0.038 \\
\hline
\end{tabular}

Table 10. The mean t-test for differences in the happiness of the first and second children of families with two girls.

\begin{tabular}{ccccccccc}
\hline & obs 1 & obs 2 & Mean 1 & Mean 2 & dif & St_Err & t_value & $p_{-}$value \\
\hline $\begin{array}{c}\text { Happiness } \\
\text { by Arank 2 }\end{array}$ & 341 & 290 & 4.006 & 3.945 & 0.061 & 0.076 & 0.8 & 0.424 \\
\hline
\end{tabular}

This paper uses empirical methods to reveal the influence of birth order on subjective well-being. This is not to suggest that individuals have the idea that my birth order determines my happiness. After all, we can see from the above that the influence of personal birth order on subjective well-being is only one aspect, and there are other more factors creating greater constraints or promoting effects. The purpose of this article is to help individuals better understand themselves and realize that their happiness may be affected by such an unexpected factor. Normally, an individual's birth order is immutable, but that doesn't mean we're helpless. As the article points out, people born in the same order often have some of the same traits, and these traits may affect the happiness of people born in different orders. Future research can further explore what causes birth order to affect happiness and what mechanisms play a role. Perhaps we can be inspired to take measures to improve happiness.

\section{Conflicts of Interest}

The author declares no conflicts of interest regarding the publication of this paper.

\section{References}

Adler, A. (1998). What Life Could Mean to You. Hazelden Publishing, Minnesota.

Becker, G. S. (1981). A Treatise on the Family. NBER Books.

Behrman, J. R. (1997). Intrahousehold Distribution and the Family. Handbook of Population and Family Economics, 1, 125-187. https://doi.org/10.1016/S1574-003X(97)80021-9

Black, S. E., Devereux, P. J., \& Salvanes, K. G. (2005). The More the Merrier? The Effect of Family Size and Birth Order on Children's Education. The Quarterly Journal of Economics, 120, 669-700. https://doi.org/10.1162/0033553053970179

Chen, G., \& Li, S. (2012). How Can the Government Make People Happy? An Empirical Study of Government Quality Affecting Residents' Happiness. Management World, 8 , 55-67.

De Haan, M., Plug, E., \& Rosero, J. (2014). Birth Order and Human Capital Development Evidence from Ecuador. Journal of Human Resources, 49, 359-392. 
https://doi.org/10.1353/jhr.2014.0008

Easterlin, R. A. (1995). Will Raising the Incomes of all Increase the Happiness of All? Journal of Economic Behavior \& Organization, 27, 35-47. https://doi.org/10.1016/0167-2681(95)00003-B

Ferrer-i-Carbonell, A. (2005). Income and Well-Being: An Empirical Analysis of the Comparison Income Effect. Journal of Public Economics, 89, 997-1019. https://doi.org/10.1016/j.jpubeco.2004.06.003

Frey, B. S., \& Stutzer, A. (2002). What Can Economists Learn from Happiness Research? Journal of Economic Literature, 40, 402-435. https://doi.org/10.1257/jel.40.2.402

Frijters, P., Haisken-DeNew, J. P., \& Shields, M. A. (2004). Investigating the Patterns and Determinants of Life Satisfaction in Germany Following Reunification. Journal of Human Resources, 39, 649-674. https://doi.org/10.2307/3558991

Furdyna, H. E., Tucker, M. B., \& James, A. D. (2008). Relative Spousal Earnings and Marital Happiness among African American and White Women. Journal of Marriage and Family, 70, 332-344. https://doi.org/10.1111/j.1741-3737.2008.00485.x

Jayachandran, S., \& Pande, R. (2017). Why Are Indian Children So Short? The Role of Birth Order and Son Preference. American Economic Review, 107, 2600-2629.

Jiang, Y. J., \& Bai, L. (2009). Research on the Relationship between College Students' Subjective Well-Being and Temperament. Psychological Science, 32, 1479-1482. https://doi.org/10.1257/aer.20151282

Jin, J., \& He, L. H. (2012). Does Education Make People Happy? Based on the Empirical Analysis of Urban Residents in Wuhan. Economic Review, 6, 36-43.

Li, L., Liu, P. C., \& Sun, S. (2017). Men and Women, Who Is Happier. Statistical Research, 7, 84-95.

Li, T., Shi, Y. P., \& Chen, B. K. (2011). Housing and Happiness: The Housing Problem of Chinese Urban Residents from the Perspective of Happiness Economics. Economic Research, 9, 69-82.

Lu, F. W., Liu, G. E., \& Li H. W. (2017). Children's Gender and Parental Well-Being. Economic Research, 10, 175-190.

Lu, Y. P., \& Wang, T. (2010). A Review of Researches on the Influencing Factors of Subjective Well-Being. Economic Trends, 5, 125-130.

Luo, C. L. (2009). Absolute Income, Relative Income, and Subjective Well-being: An Empirical Analysis Based on China's Urban and Rural Household Survey Data. Finance and Economics Research, 35, 79-91.

Luo, K., \& Zhou, L. (2010). The Impact of Children's Birth Order and Gender Differences on Human Capital in Education: An Analysis Based on the Perspective of Family Economics. Economic Science, 32, 107-119.

Luo, Z. L., \& Li, Y. (2017). On the Influence of Birth Order on Individual Development. Campus Psychology, 15, 193-197.

Ohtake, F. (2012). Unemployment and Happiness. Japan Labor Review, 9, 59-74.

Price, J. (2008). Parent-Child Quality Time Does Birth Order Matter? Journal of Human Resources, 43, 240-265. https://doi.org/10.3368/jhr.43.1.240

Tian, G. Q., \& Yang, L. Y. (2006). An Answer to the "Happiness-Income Puzzle". Economic Research, 11, 4-15.

Tian, L. (2004). A Summary of Subjective Well-Being and Its Relationship with Personality. Psychology and Behavior Research, 2, 469-473.

Van der Meer, P. H. (2014). Gender, Unemployment and Subjective Well-Being: Why 
Being Unemployed Is Worse for Men than for Women. Social Indicators Research, 115, 23-44.https://doi.org/10.1007/s11205-012-0207-5

Wang, T., Huang, X. T., \& Bi, C. H. (2014). The Effect of Physical Health on Chinese People's Well-Being: The Moderating Effect of Religious Belief. Chinese Journal of Clinical Psychology, 22, 1053-1056.

Weng, Q., Gao, X., He, H., \& Li, S. (2019). Family Size, Birth Order and Educational Attainment: Evidence from China. China Economic Review, 57, 101346. https://doi.org/10.1016/j.chieco.2019.101346

Yuan, Z., \& Li, L. (2017). Marriage and Well-Being: China's Micro Data Based on WVS. China Economic Issues, 1, 26-37.

Zhang, X. Z., \& Cai, G. W. (2011). Income, Values and Resident Happiness-Empirical Evidence from Guangdong Adult Survey Data. Management World, 9, 63-73.

Zhou, S. J., Wang, H. C., \& Su, Y. (2015). How Can Chinese People Have a Higher Level of Happiness-Based on the Survey of China's Livelihood Index. Management World, $6,8-21$. 